\title{
INTEGRATING REGIONAL INDUSTRIAL THEME EXAMPLES IN Process ConTrol EduCATION
}

\author{
Jean-Sébastien Deschênes \\ Département de Mathématiques, d'Informatique et de Génie, Université du Québec à Rimouski (UQAR) \\ Email: jean-sebastien_deschenes@uqar.qc.ca
}

\begin{abstract}
A process control course was elaborated around the specific regional (industrial) context in which UQAR has an important mission of regional development. A multidisciplinary approach is used, integrating notions from various fields of engineering (electrical, mechanical, chemical and civil engineering) through theme examples such as wastewater treatment, pulp and paper making, mining and metallurgical extraction (mineral grinding). Laboratory activities on such processes are realized using a simulation software specifically designed for process control education. The small size of the groups at UQAR also allows to employ innovative strategies on how to run the activities and to evaluate the students. One laboratory on a real physical system (electrical motor) was also part of the course, to balance between the advantages of the software and the more "hands-on" laboratories. General feedback and comparative appreciation from students is then presented, followed by overall conclusions.
\end{abstract}

Keywords: Control Systems: Process Control Education: Engineering Education: Simulation Software: Regional Industry.

\section{INTRODUCTION}

Student motivation is a recognized factor in academic success and student retention in an engineering curriculum [1-3]. While the actual conceptualization of motivation is quite variable, there seems to be a general agreement that a common source of motivation for engineering students is a "real-world" relevant approach [1, 2, 4]. However, it has been pointed out that real-world learning experiences are often quite complex, making their integration in academic courses difficult [2]. The development of such laboratory activities on well-chosen examples thus requires important efforts, but if well oriented, promises to provide effective results on the development of student competences.

On that level, a sense of multidisciplinarity (knowledge and ability to work across disciplines) is often noted as an increasingly required skill for engineering graduates in the current globalization context [5, 6]. Engineering education is thus under pressure to adapt to this reality, and increase the student's familiarity with "real-world" problems and solution methods, that most often imply interdisciplinary knowledge and interactions between professionals from different fields [7-11]. Students should be able to stretch out of their "comfort zone" and experience more realistic multidisciplinary situations as part of their formation. This can be achieved by a "systems approach" [5, 12], but still seldom actual implementations in the curriculum are being realized: examples of interesting reports are found for an innovative design course involving real multidisciplinary interactions between students of different disciplines [7] and a design course preceded by two multidisciplinary preparatory courses involving electrical and mechanical engineering students [8]. More specifically in the process control field, an example is found in [9], where mainly the organization structure is presented for a course taught by faculty members from two distinct departments, electrical and mechanical engineering.

At UQAR, engineering started in 1995 with one single program: electromechanical systems engineering. It was created around interdisciplinary considerations, and the vision for a more versatile formation. The regional context initially prompted such a decision, but the global "systems approach" adopted throughout the curriculum (which now also extends to our electrical and mechanical engineering programs, enforced by the NSERC-UQAR chair in design engineering, particularly through all four design courses) now proves a competitive advantage for our graduates on the global market.

This paper presents a process control course developed without distinction for students of either our engineering programs. The opportunity was seized to present students with a wide range of process control applications, and to input notions from chemical engineering and metallurgical engineering fields through process considerations, further enhancing our student's multidisciplinary background. A particular care was taken to select industrial applications from the main (major) regional economic sectors, with the objective of enhancing student interest and motivation. 
While the laboratory activities are presented here in a rather quick overview, their more detailed presentation is available in [13], recently published in the International Journal of Engineering Education. Greater emphasis is put here on the rationale for the activities, however.

\section{COURSE ORGANIZATION}

\subsection{Generalities}

The regional situation and mission of UQAR, being at the heart of a rather vast and sparingly populated territory, reflects on the small class sizes (20-30 students). Such a situation is known to increase learning opportunities [14], and favors teacher's availability to students. Commitment of the teacher and his degree of engagement towards the class are also known factors to impact student motivation positively [1]. Since motivated students are most likely to succeed and complete their program, this incentive should not be neglected in course and curriculum development.

All laboratory activities were built in a specific context (a very concrete industrial process) to provide relevance to the task. The number of laboratories was limited to four (4), although their duration are variable and cover every week of the semester: the idea was to set conditions that would favor the adoption of a "deep" learning style by the students (on a limited number of situations), as there are indications that a too high quantum of content can cause the students to revert to a "surface" learning style to limit their risk of failing a course [1].

The laboratory activities (and most of their evaluations methods) were set to maximize the learning potential and development of competences. The first two activities were developed to favor the construction of knowledge by the student themselves, in part by setting an open-ended goal (a form of "challenge" to a certain extent). The evaluation is in the form of an oral presentation, including a period of questions, plus an actual evaluation of their solution. The two others laboratories were in the more classic form of a directed laboratory with the evaluation of a written report (including all necessary discussions, conclusions, etc.).

A software simulator (specifically intended for process control education [15]) was used for most activities, thus allowing such a variety of processes. Many studies reveal that software laboratories can be at least as effective (and in some cases even more) as the more hands-on laboratory [4, 16, 17], although most students still express a general preference for the hands-on type [4]. One such laboratory (on a real physical system) was included in the course to balance between the advantages of software versus handson laboratories.

This course follows a first introductory linear analysis course and another linear control course, and is intended for third-year undergraduate students in engineering.

\subsection{Wastewater treatment (anaerobic digestion)}

This first laboratory was set up to provide a "physical" basis for an unstable process, and to introduce notions to students about bioprocesses. Bacterial growth (associated factors), substrate consumption, metabolite excretion, and general process kinetics are examples. Specifics about the "methanization" process are also introduced.

The process considered involves two (2) populations of bacteria (acetogenics and methanogenics), which compete for survival in a bioreactor. Through manipulation of $\mathrm{pH}$, the (exponential) growth of one population can be favored over the other. The objective is to maintain a certain ratio of these populations for the process to function effectively (at a supposed optimum ratio). The process dynamics are typical of unstable processes, and the associated reasoning of the physical system is also compatible.

Essentially, the situation may simply be viewed as the control of an unstable system with dead time, with the objective of obtaining the best control performances as it is possible, evaluated on the settling time ( $\pm 5 \%$ corridor) of the closed-loop (step-response). Students are expected to be able to explain their results in terms of what happens at the physical level in the process.

The task is attributed to teams of 2 to 3 students, over a duration of 3 weeks. During the first week, a basic control algorithm is suggested to students (internal $\mathrm{P}$ and external PI(D) loops), which provides a variety of possible tunings. During the second week, they have to search through the (scientific) literature to find other alternative algorithms or tuning approaches and implement successfully at least one of them. The third week is devoted to the last fine tuning of their solutions, and formalizing a recommendation.

As mentioned earlier, the evaluation takes the form of an oral presentation, where students should summarize the process situation, their methodology, the main results and answer specific questions. This part of the evaluation is worth $80 \%$ of the mark. The remaining $20 \%$ is attributed proportionally to the actual performances of the algorithm, in a somewhat "competitive" fashion. An all-competitive form of evaluation is not necessarily motivating for many students [14], but it does have its appeal for some people. By keeping this element of evaluation to carry a relatively small weight, we believe to reduce the risk of diminishing motivation. For each team presentation, one other team of students (selected at random) is involved in the evaluation process: this showed to have a positive impact on student implication.

Results showed that student teams were able to realize original control designs and demonstrate their ability to analyze and understand rather complex research papers on control engineering. They proved effective in their ability to analyze control performances using main recognized standards in the field. 


\subsection{Pulp and paper making}

This second laboratory, in a similar fashion as the first, was used as a physical basis for a nonlinear system, and to provide notions about paper making. The (simple) process considered is the mixing of concentrated pulp and white water (for the pulp consistency control) at the wet end of a paper machine. The process configuration allows the pulp from the inventory and white water (dilution stream) to be mixed before a variable-speed driven pump, which is used to provide the total "furnish flow" to the paper machine. This configuration allows for a better mixing of the fluids, as it benefits from the turbulence inside the pump head. A consistency sensor is installed after a certain pipe length downstream from the pump, based on the manufacturer's specifications (for accurate measurement and laminar flux considerations). The objective is to keep the consistency at a constant value despite possibly important variations in the furnish flow (which is proportional to the speed of the paper machine), by acting on the proportional valve of the white water addition (dilution stream).

From a control point of view, this configuration has a nonlinear behavior on both the process gain and the dead time, both inversely proportional to the furnish flow (fixed by the variable-speed pump). The objective is to regulate effectively the consistency despite important variations in the furnish flow (up to a factor of 10). Again, the openended objective is to obtain the best control performances at both the nominal operating point, and at a furnish flow 10 times lower. Both pursuit and regulation responses are evaluated at both operating points.

This laboratory has a duration of five (5) weeks. A side objective of the course is to show students a methodology for actuators sizing (mainly pumps and valves) for control applications. The first week of the activity is thus used for sizing the actuators, based on process specifications (flow and consistency at nominal operation, and at a maximum possible operation point). The second week is dedicated to the identification of the relevant process transfer functions and the implementation of a simple PI control algorithm, and its combination with static or dynamic feed-forward control. The limitations of these control strategies are then to be assessed in relation to the admissible decrease in the furnish flow. In week 3 , students work on implementing a ratio control strategy, and compare results with previous control strategies. Finally, weeks 4 and 5 are dedicated to literature review to find additional control algorithms that could potentially provide better performances in this case.

As in the previous case, the evaluation takes the form of an oral presentation, where students have to summarize the process situation, their methodology, main results, and answer questions. This part is again worth for $80 \%$ of the total mark. The other $20 \%$ is again a function of the actual performances of the algorithm, in a similarly competitive fashion. Also again in this case, each team presentation is being evaluated by another student team.

Results showed similar observations as in the previous case: students proved competent in implementing original control strategies and in their ability to analyze complex research papers on control engineering, as well as discuss performance issues using the standards of the field.

\subsection{Electrical motor (DC)}

This laboratory involves a real physical system (handson laboratory), an electrical (DC) motor. The objective is to control the rotational speed, while maintaining the input current within acceptable limits to avoid possible damage to the engine. This is realized by implementing a cascade control structure, with the internal loop set on controlling the input current, and external loop set on controlling the rotational speed of the motor. The constraints on the input current correspond to the anti-reset values of the external loop PI(D) controller.

Students are once again organized in teams of about 23 students, and the laboratory implies a series of elements to test and discuss in the form of a written report. All the experiments take place within a single lab period, and they involve: system identification on the rotational speed and input current, implementation of a SISO loop on the speed and observation on the signal form of the input current, implementation of an input current loop and identification of the transfer function between its set-point and the motor rotational speed, and final implementation and discussions on the results for both signals in various situations (pursuit and regulation).

\subsection{Mineral grinding}

This laboratory is realized with the software simulator, since operating an real mineral grinding circuit would not actually be possible in an educational context. The circuit considered is illustrated in Fig. 1, and it is a multivariable process. It is a common setup used as the preparation step for the separation of valuable mineral from undesirable gangue material. Its objective is to reduce the size of ore particles, so they are prepared for the next separation step appropriate to the mineral of value to be recuperated (e.g. flotation). Configurations for this process often include a rod mill for the primary grinding of the coarse mineral and a ball mill for the secondary grinding of the mineral into smaller particle sizes. In some cases, the grinding circuit can include only one mill, while a primary crusher ensures the first action of particle size reduction before supplying the mineral to the conveyor, which is the considered case.

The manipulated inputs to the system are the total mill feed rate and water addition to the sump box. The outputs are the mill circulating load, and the particle product size. 
Appropriate control strategies can be either decentralized, or "multivariable" (i.e. with the use of decouplers).

The activity is realized over two weeks, during which students are required to implement their strategies in the simulator, and compare the performance results following set-point changes and disturbance rejection tests (the main source of disturbance in a mineral grinding circuit being the composition of the mineral feed, with corresponding hardness and particle size distribution of high variability). This is another more "classic" laboratory form, for which a written lab report (with necessary discussions) has to be handed in.

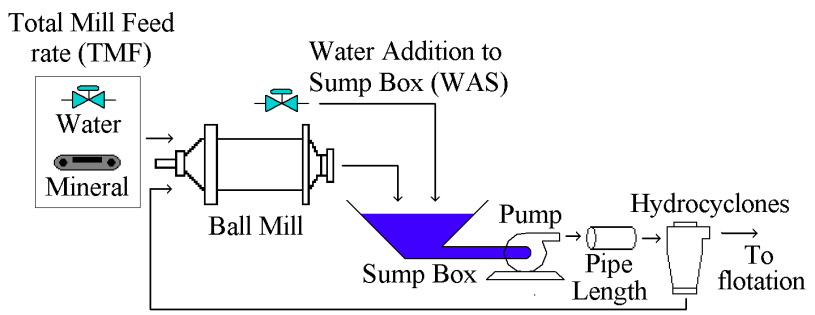

Fig. 1. Mineral grinding circuit under consideration.

\section{STUDENT FEEDBACK AND RESULTS}

The course was offered on a yearly basis over the last four (4) years, and student feedback data was collected for the three first years (2008, 2009 and 2010). A very simple survey was elaborated to gauge student preferences, their satisfaction about the software tools, and their general appreciation of course contents. The survey also allowed space for comments or justifications. The survey was not distributed in 2011, but class results (a measure of student performance) were compiled.

\subsection{Student feedback}

After the first elaboration of the survey in 2008, a few adjustments were in order for the following years. Among others, it was specified to circle only one answer at Q1, and two new options were added for Q3, being to slightly reduce the number of processes, or slightly augment this number. Results not adding up to $100 \%$ are due to some student invalid responses (year 2008 only).

Normal student attendance for the course is between 15 and 20 students. However, year 2010 low attendance (8) is due to a change in program course planning from year \# 3 to year \# 4. This had for effect that only the students that had to graduate this year took the course. In 2011, student attendance was back to normal with 16 students.

A first tendency that can be drawn from the results is that the most popular laboratory activity, year after year, remains the hands-on laboratory involving the industrial programmable controller (always between $40 \%$ to $50 \%$ of students), which is in accordance with the literature [4]. However, this also tells us that at least half of the students always still preferred one of the software laboratories, and this is an interesting result. Some variability is noticed in the answers from year to year, which could be attributed to the specific interests of the individual students present at the time. Despite the general preference for the handson physical system, almost all students (except two in the first year) have appreciated the simulation laboratories. Dissatisfaction of the two students the first year could be attributed to the laboratories not being fully proofed that year, and that Matlab had not been previously introduced to the students at that time (2008). However, this is a very high satisfaction level, repeatedly attained the two other years once these aspects were more correctly addressed. The last thing reported in the results is that the majority (60\% to $77 \%$ ) of students feel the variety of processes is adequate for the course, year after year. They feel such a variety provides a sufficient span of applications for an overview of the control engineering discipline.

Table 1: Survey questions.

\begin{tabular}{|c|c|c|c|}
\hline & 2008 & 2009 & \\
\hline Responses & $17(19)$ & $15(16)$ & (8) \\
\hline Student we & $5.9 \%$ & $6.7 \%$ & $.5 \%$ \\
\hline \multicolumn{4}{|l|}{ Q1. Which course labora } \\
\hline a) $\mathrm{Was}$ & $23.5 \%$ & $20.0 \%$ & $5.0 \%$ \\
\hline & & & $0 \%$ \\
\hline & & $\%$ & $0.0 \%$ \\
\hline l) $\mathrm{N}$ & $11.8 \%$ & $13.3 \%$ & $0.0 \%$ \\
\hline \multicolumn{4}{|c|}{$\begin{array}{l}\text { Q2. Did you appreciate the use of the simulator in the } \\
\text { context of the course, considering it allowed to address } \\
\text { specific processes which would not have been possibly } \\
\text { addressed otherwise? }\end{array}$} \\
\hline ) $\mathrm{Ye}$ & $\begin{array}{l}88.2 \% \\
11.8 \%\end{array}$ & $\begin{array}{l}100 \% \\
0 \%\end{array}$ & $\begin{array}{l}100 \% \\
0 \%\end{array}$ \\
\hline \multicolumn{4}{|c|}{$\begin{array}{l}\text { Q3. Looking back at the course now, you consider that } \\
\text { process variety should be: }\end{array}$} \\
\hline & $76.6 \%$ & 60.0 & $75.0 \%$ \\
\hline & & & \\
\hline & & & $12.5 \%$ \\
\hline $\begin{array}{l}\text { d) Diminished to a single one } \\
\text { orocess. }\end{array}$ & $17.6 \%$ & $13.3 \%$ & $12.5 \%$ \\
\hline
\end{tabular}

From student's comments, most of them expressed that the use of the simulator was very interesting, and that it has helped them focus on the control itself rather than on physical system operation constraints. A few international students felt the course was a very interesting opportunity to learn about eastern Quebec's most important industrial sectors. 


\subsection{Student success}

An assessment of student success can be related to the course results. The difficulty level of the course itself (and the exams) has actually increased over the years, linearly (approximately, in the author's mind) from 2008 to 2011. During these years, the laboratory activities and protocols were also improved each year and starting in 2010, a more detailed procedure (i.e. clearer identification of the steps) was provided for the open-ended challenge activities.

The average grades on the exams (two partial exams) the final grade of the course (\%) are analyzed. Results are shown in Fig. 2, where a positive correlation is observed between exam success and the final grade: although this is rather obvious, what it actually means is that students did not succeed the course only because they did well on the laboratories (except perhaps in 2009, where the group was particularly weak): their success at this level generally has an impact on their success at exams. Yearly improvements and clarifications made to the activities seem to generally have an impact on student learning efficiency, despite the increasing difficulty level of the course.

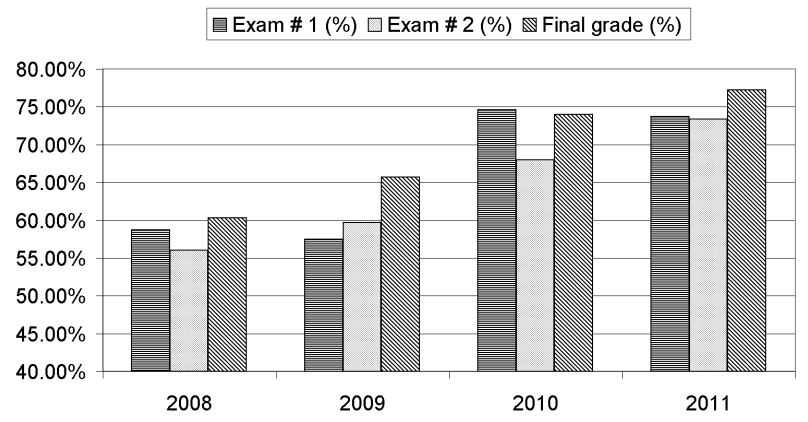

Fig. 2. Exams and final grade results (2008, $N=19$; 2009, $N=16 ; 2010, N=8 ; 2011, N=16$ ).

Note that the passing mark for the course is $50 \%$, and that this same average mark was necessary on the exams to pass the course since 2010 (after the year 2009 group situation). This could also have played a role in the higher success rate in 2010 and 2011 suggesting that our students are more effectively extrinsically motivated (with an aftereffect on intrinsic motivation).

Distribution of grades is shown in Fig. 3, where a more detailed view of student success can be seen. Notation at UQAR uses a grading system ranging from $\mathrm{E}$ (failure) to $\mathrm{A}+$ (ultimate measure of success). Grades from A to $\mathrm{C}$ can have + or - modifiers, while $\mathrm{D}$ can only have a + modifier (E is directly blow D). To simplify the results presentation all grades of a similar letter (whatever the grade modifier) were regrouped.

What these more detailed results show is that the better average results are not only explained due to a minority of very strong students, but indeed to a global higher success of the entire class. Also of interest is that no failing grades were attributed in the last two years. Also, despite the low average mark in the first years, student satisfaction for the course (from course evaluations) was always above $85 \%$ to $90 \%$ in all evaluation sections. This also reinforces the fact that "not only easy teachers (easy graders) get good student evaluations" [18].

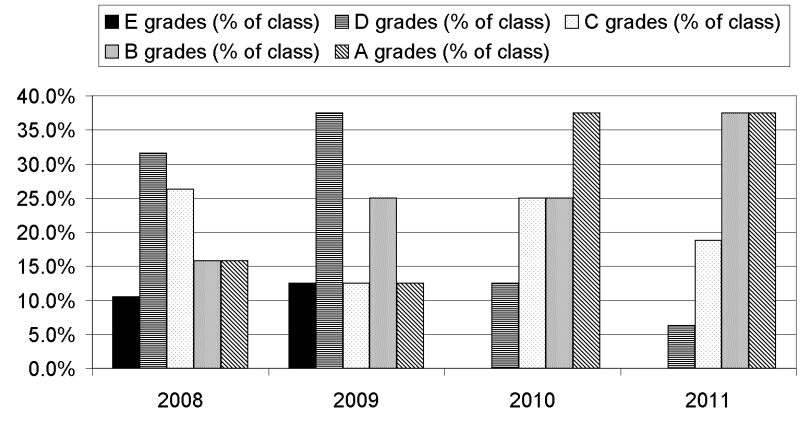

Fig. 3. Grade distribution results $(2008, N=19 ; 2009$, $N=16 ; 2010, N=8 ; 2011, N=16)$.

\section{CONCLUSIONS}

This paper presented the rationale for the laboratories of a process control course at UQAR, taking into account motivation factors, learning possibilities and development of competences. Activities were mainly conducted using a simulation software, focused on regional industrial theme examples to enhance interest and motivation. The use of a simulator allowed a high degree of interactivity, and quick feedback to students on the impacts of their modifications on the algorithms themselves or the tunings (thus favoring an active construction of knowledge). It even "saves the trouble" of operating a real system and really focus on the control itself, which is really the goal of the course.

Feedback from students was provided (over three years of usage in class) as well as student success results. It was shown that while the laboratory with the physical system was the most popular, more than half of the students still repeatedly preferred either one of the other laboratories (software), depending on personal interests. Over the last two years, all (100\%) students have confirmed that they well appreciated the software laboratories in the course, and were happy about the variety of subjects it allowed to cover. Overall results showed good student implication and high interest throughout the activities. It helped them develop their skills on communicating scientific contents orally to colleagues, in addition to more common written reports. The open challenges proved an effective mean for students to develop confidence and autonomy on control systems design. Improvement of the activities appears to have had a positive impact on student success, despite the increasing level of difficulty of the course over the years. 
In a future work, survey questions should be improved to include a more detailed student evaluation of different laboratory aspects, and their own perspective on what they contributed to achieve on a personal level (development of competences). Initial characterization of the student's intrinsic versus extrinsic motivation factors could also be included to help further analyze the results.

\section{References}

[1] Nick Savage, Roy Birch and Eleni Noussi, "Motivation of engineering students in higher education," Engineering Education, vol. 6, no. 2, pp. 39-46, 2011.

[2] Jennifer Turns, Kathleen Gygi and Michael J. Prince, "How Engineering Educators Take Student Motivation into Account," in Proceedings of the Research in Engineering Education Symposium, 2009, Palm Cove, QLD.

[3] Brian F. French, Jason C. Immekus and William C. Oakes, "An Examination of Indicators of Engineering Student's Success and Persistence," Journal of Engineering Education, vol. 94, no. 4, pp. 419-425, 2005.

[4] James E. Corter, Sven K. Esche, Constantin Chassapis, Jing Ma, and Jeffrey V. Nickerson, "Process and Learning Outcomes from Remotely-Operated, Simulated and Handson Laboratories," Computers and Education, vol. 57, pp. 2054-2067, 2011.

[5] Doris Kilbane, "Career Paths: Today's Tough Job Market Calls For Versatility," Electronic Design, vol. 52, no. 13, pp. 89-95, 2004.

[6] Jack Cator and Alex Bates, Striving to Recruit and Retain the Best and Brightest Engineering Students. Duke University Center on Globalization Governance and Competitiveness, 2006, Accessed 5 July 2010, http://www.cggc.duke.edu/pdfs/papers/cator_bates_2.pdf

[7] Zhilbert Tafa, Goran Rakocevic, Djordje Mihailovic and Veljko Milutinovic, "Effects of Interdisciplinary Education on Technology-Driven Application Design," IEEE Transactions on Education, vol. 54, no. 3, pp. 462-470, 2011.

[8] Kevin Craig and Mark Nagurka, "Multidisciplinary engineering systems $2^{\text {nd }}$ and $3^{\text {rd }}$ year college-wide courses," in Proceedings of the 2010 IEEE Conference Transforming Engineering Education: Creating Interdisciplinary Skills for Complex Global Environments, 6-9 April, 2010, pp. 1-15.
[9] Robert Rabb, John Rogers, and David Chang, "Course development in interdisciplinary controls and mechatronics," in Proceedings of the $38^{\text {th }}$ ASEE/IEEE Frontiers in Education Conference, 22-25 October 2008, pp. T3F-11 - T3F-15.

[10] National Academy of Engineering, Educating the Engineer of 2020: Adapting Engineering Education to the New Century. Washington, DC: National Academies Press, 2005, 208 pp. \{ISBN: 978-0309-09649-2 \}

[11] Susan Blanchard, Robert O'Neill, James Sweeney, Lisa Zidek, Simeon Komisar and Diana Stoppiello, "Reinventing engineering education one new school at a time," in Proceedings of the ASEE Annual Conference and Exposition, Louisville, KY, 20-23 June 2010, 14 pp., 2010.

[12] Thomas F. Edgar, Babatunde A. Ogunnaike, James J. Downs, Kenneth R. Kuske and B. Wayne Bequette, "Renovating the undergraduate process control course," Computers and Chemical Engineering, vol. 30, no. 10-12, pp. 1749-1762, 2006.

[13] Jean-Sébastien Deschênes, "Integration of local industry theme examples in process control education: a case from North-Eastern Quebec," International Journal of Engineering Education, vol. 27, no. 6, pp. 1383-1393, 2011.

[14] Judith L. Meece, Eric M. Anderman and Lynley H. Anderman, "Classroom Goal Structure, Student Motivation, and Academic Achievement," Annual Review of Psychology, vol. 57, pp. 487-503, 2006.

[15] Jean-Sébastien Deschênes, Développement d'outils pour l'enseignement de la commande automatique. Masters dissertation, Département de génie électrique et de génie informatique, Université Laval, Québec, August 2002.

[16] Lyle D. Feisel and Albert J. Rosa, "The Role of the Laboratory in Undergraduate Engineering Education," Journal of Engineering Education, vol. 94, no. 1, pp. 121130, 2005.

[17] Romanas V. Krivickas and Jonas Krivickas, "Laboratory Instruction in Engineering Education," Global Journal of Engineering Education, vol. 11, no. 2, pp. 191-196, 2007.

[18] Richard Felder, "What Do They Know Anyway?" Chemical Engineering Education, vol. 26, no. 3, pp. 134135, 1992. 